\title{
Análise econômica da suplementação protéico-energética de novilhos durante o período de transição entre água-seca
}

\author{
[Economic analysis of protein and energy supplementation of steers during the transition \\ period between the rainy and dry seasons] \\ F.A. Barbosa $a^{1,3}$, D.S. Graça², P.H.S. Guimarães ${ }^{1}$, F.V. Silva Júnior ${ }^{3}$ \\ ${ }^{1}$ Aluno de pós-graduação - EV-UFMG \\ ${ }^{2}$ Escola de Veterinária - UFMG \\ Caixa Postal 567 \\ 30123-970 - Belo Horizonte, MG \\ ${ }^{3}$ Instituto de Tecnologia Brasil Pecuária - Belo Horizonte, MG.
}

\begin{abstract}
RESUMO
Avaliou-se economicamente o efeito da suplementação protéico-energética em dois níveis de ingestão diária, $0,17 \%$ e $0,37 \%$ do peso vivo, sobre o desempenho de novilhos, em pastagens de Brachiaria brizantha cv. Marandu utilizando-se 14 animais por tratamento. Os tratamentos foram: SM - suplementação mineral (controle), SUP1 - suplementação protéico-energética com média de ingestão diária de $0,17 \%$ do peso vivo e SUP2 - suplementação protéico-energética com média de ingestão diária de $0,37 \%$ do peso vivo. Novilhos que receberam a suplementação protéico-energética SUP1 e SUP2 apresentaram maiores ganhos de peso, 0,655 e $0,746 \mathrm{~kg} / \mathrm{animal} / \mathrm{dia}$, respectivamente em relação aos que receberam apenas suplementação mineral, 0,535kg/animal/dia. Os maiores lucros operacionais, observados para os animais dos tratamentos SUP1 e SUP2. 67,12 e 72,08 R\$/animal/período, respectivamente, em relação aos do tratamento controle, 66,67 $\mathrm{R}$ \$animal/período; os resíduos para remuneração foram de $\mathrm{R} \$ 59,92, \mathrm{R} \$ 55,10$ e $\mathrm{R} \$ 54,85 /$ animal/período, para novilhos que receberam SUP2, SUP1 e SM, respectivamente e sugerem que a suplementação protéicoenergética possibilitou maior retorno econômico.
\end{abstract}

Palavras-chave: novilho, desempenho, custo, lucro, pasto

\begin{abstract}
The effects of protein and energy supplements at two levels of daily intake - $0.17 \%$ and $0.37 \%$ of live weight $(L W)$ - on the performance of steers under Brachiaria brizantha $c v$. Marandu pasture were economically evaluated using 14 steers per treatment. Treatments were: MS - mineral supplementation (control), SUP1 protein and energy supplementation with an average daily intake of $0.17 \%$ of live weight, and SUP2 - protein and energy supplementation with an average daily intake of $0.37 \%$ of live weight. Steers of treatments SUP1 and SUP2 showed higher weight gains, 0.655 and $0.746 \mathrm{~kg} /$ animal/day, respectively, in relation to those in the control group, $0.535 \mathrm{~kg} /$ animal/dia. Higher operational profits were observed, R\$67.12/animal/period and R\$72.08/animal/period, for steers from SUP1 and SUP2 treatments, respectively; in comparison to the $R \$ 66.67 /$ animal/period for MS treatment. The residual remunerations of $R \$ 59.92, R \$ 55.10$, and $R \$ 54.85 /$ animal/period, for steers from SUP2, SUP1, and SM, respectively, strongly suggest that energyprotein supplementation allow higher economic profit.
\end{abstract}

Keywords: steers, performance, cost, profit, pasture

\section{INTRODUÇÃO}

Pastagens, geralmente, não contêm todos os nutrientes essenciais, na proporção adequada de forma a atender às exigências dos animais em

Recebido em 28 de agosto de 2007

Aceito em 14 de abril de 2008

E-mail: fabianoalvim@superig.com.br pastejo; portanto, o suplemento deve ser considerado como complemento da dieta, para suprir os nutrientes deficientes na forragem disponível (Reis et al., 1997).

A necessidade de prover suplemento protéico, energético e mineral aos bovinos em pastagens e as 
quantidades a serem fornecidas dependem das metas a serem atingidas de acordo com o planejamento de ganho de peso proposto na propriedade. Essa suplementação depende da qualidade e da disponibilidade de matéria seca do pasto (Barbosa et al., 2007).

Outros fatores também podem estar relacionados, como o recurso financeiro disponível, as características dos animais (idade, raça e estádio fisiológico), infra-estrutura de cochos e de bebedouros e a mão-de-obra (Carvalho et al., 2003).

Mesmo na estação chuvosa, quando, aparentemente, as pastagens podem atender às demandas nutricionais dos animais, a suplementação de proteína e energia pode ser benéfica. Segundo Paulino et al. (2002) e Goes et al. (2003), a suplementação de proteína durante a estação chuvosa proporcionou ganho adicional diário de 160 a 300g/animal.

O fornecimento de 1,0 a $1,5 \mathrm{~kg} / \mathrm{animal} / \mathrm{dia}$ de suplemento protéico rico em farelo de soja, de algodão e linhaça, junto com minerais e vitaminas, complementa a dieta de bovinos, em pastagens de baixa qualidade, permitindo ganhos diários acima de $0,5 \mathrm{~kg}$ com custos econômicos. E, ainda, se 30 a $60 \%$ da proteína vegetal for substituída por equivalente em uréia nas misturas, o custo será reduzido e serão mantidos os mesmos ganhos de peso (Loosli e McDonald, 1969).

Dentre os procedimentos utilizados para a avaliação econômica da atividade agropecuária, o custo de produção é um dos principais critérios, e pode ser definido pela soma dos valores de todos os recursos que são utilizados no processo produtivo de uma atividade (Frank, 1978; Reis, 2002). A análise econômica é a comparação da receita obtida com os custos da atividade produtiva, e inclui, em alguns casos, os riscos, o que permite a verificação da remuneração dos recursos empregados no processo produtivo são remunerados (Reis, 2002).

O uso de suplementos alimentares, no sistema de produção de bovinos, ocasiona maior desembolso de capital no início do trabalho. Para que essa técnica seja difundida é necessário que seja economicamente viável. $\mathrm{O}$ ganho em peso do animal tem de pagar o investimento com a suplementação e os outros custos de produção. Além disso, deve ser levado em consideração que o animal que recebeu suplemento poderá sair mais rápido da pastagem, reduzindo o custo de permanência e permitindo a entrada de nova categoria animal, com aumento de giro de capital.
Moraes et al. (2006) verificaram redução dos dias de suplementação necessários para o abate (DPA) de bovinos quando forneceram suplemento com 24\% de PB, em pastagens de Panicum maximum cv. Mombaça, na época de transição seca-água.

O objetivo deste trabalho foi avaliar economicamente o efeito de dois níveis de suplementação protéico-energética sobre o desempenho de novilhos, na fase de recria, durante a época de transição água-seca, em pastagens de Brachiaria brizantha.

\section{MATERIAL E MÉTODOS}

O trabalho foi desenvolvido na Fazenda Invernada, localizada no município de Cachoeira da Prata, MG, na região metropolitana de Belo Horizonte. O período experimental foi de 15 de fevereiro a 14 de junho de 2003, adotando-se 14 dias iniciais para adaptação dos animais.

A área experimental era composta de três piquetes de pastagens de Brachiaria brizantha cv. Marandu, cada um com 14ha efetivos. Foi adotado o sistema de pastejo contínuo, com taxa de lotação variável e média de 1,23 unidade animal $(1 \mathrm{UA}=450 \mathrm{~kg}$ de peso vivo)/ha.

A avaliação de desempenho foi feita utilizando-se, por tratamento, 14 novilhos não castrados, cruzados (Holandês x Gir), com média de 12 meses de idade e $211 \mathrm{~kg}$ de peso vivo inicial. Os novilhos foram pesados a cada 21 dias; a pesagem inicial e a pesagem final foram precedidas de 14 horas de jejum absoluto de água e de alimento. Nas pesagens intermediárias não houve jejum prévio.

$\mathrm{O}$ delineamento experimental foi inteiramente ao acaso, com três tratamentos: controle (SM); suplementação protéico-energético com ingestão de $0,17 \%$ do peso vivo (SUP1) e suplementação protéico-energética com ingestão de $0,37 \%$ do peso vivo (SUP2) (Tab. 1).

O suplemento protéico-energético foi formulado com o objetivo de atender, no mínimo, $40 \%$ da necessidade protéica de um novilho inteiro de $250 \mathrm{~kg}$, com ganho diário de 0,7 a $1,0 \mathrm{~kg}$, isto é, ingestão de 600 a $750 \mathrm{~g} /$ dia de proteína bruta (PB) (Nutrient ..., 1996; Silva et al., 2002).

Os dados foram analisados pelo método dos quadrados mínimos, por meio do procedimento PROC GLM do pacote estatístico SAS (User's ..., 1990). Para a comparação entre as médias, adotouse $o$ teste $t$, e todas as análises foram feitas para $o$ nível de significância de 5\%, seguindo 
recomendações de Sampaio (2002). O modelo matemático foi o seguinte:

$Y_{i j}=\mu+T_{i}+P I_{j}+e_{i j}$, em que:

$\mathrm{Y}_{\mathrm{ij}}=$ ganho do animal i pertencente ao tratamento $\underline{\mathrm{i}}$;

$\mu=$ média do efeito;

$\mathrm{T}_{\mathrm{i}}=$ efeito fixo do tratamento $\underline{\mathrm{i}},(\mathrm{i}=1,2,3)$;

$\mathrm{PI}_{\mathrm{j}}=$ covariável (peso inicial do animal i);

$\mathrm{e}_{\mathrm{ij}}=$ erro aleatório associado a cada animal.
$\mathrm{Na}$ composição dos custos totais (CT) foram considerados os valores de custos anuais divididos pelo total do número de animais da propriedade (176 novilhos), divididos por 365 dias e, posteriormente, multiplicados por 105 dias (duração do experimento).

Tabela 1. Composição centesimal do suplemento mineral (SM) e dos suplementos protéico-energéticos (SUP1 e SUP2) e seus respectivos preços (R\$/kg) e teores de proteína bruta (PB) e nutrientes digestíveis totais (NDT)

\begin{tabular}{lccc} 
& SM & SUP1 & SUP2 \\
\hline Farelo de soja (\%) & - & 60 & 15 \\
Polpa cítrica (\%) & - & 13 & 63 \\
Uréia (\%) & - & 11 & 7 \\
Melaço em pó (\%) & - & 7 & 10 \\
Suplemento mineral (\%) & - & 4,6 & 2,6 \\
Cloreto de sódio (\%) & 49,0 & 3,2 & 1,6 \\
Fosfato bicálcico (\%) & 41,1 & - & - \\
Calcário calcítico (\%) & 9,203 & - & - \\
Sulfato de cobre (\%) & 0,41 & - & - \\
Sulfato de manganês (\%) & 0,12 & - & - \\
Sulfato de cobalto (\%) & 0,007 & - & - \\
Oxido de zinco (\%) & 0,16 & - & 0,8 \\
Sulfato de amônio (\%) & - & 1,2 & 100 \\
\hline Total (\%) & 100 & 100 & 0,422 \\
\hline R $\$$ kg & 0,640 & 0,595 & 39,19 \\
\hline PB (\%) & - & 69,44 & 79,23 \\
NDT (\%) & - & 74,62 & \\
\hline
\end{tabular}

Testimado pela equação: NDT= DIVMS - cinzas + 1,25 EE + 1,9 (Van Soest, 1994).

Analiticamente, a equação de custo foi:

$\mathrm{CT}=\mathrm{Px}_{1} \mathrm{X}_{1}+\ldots \ldots \mathrm{Px}_{\mathrm{n}} \mathrm{X}_{\mathrm{n}}+\mathrm{K}, \mathrm{em}$ que

$\mathrm{Px}_{1, \mathrm{n}}=$ custos dos fatores variáveis;

$\mathrm{X}_{\mathrm{n}}=$ quantidade de fatores variáveis utilizados; $\mathrm{K}=$ custo dos fatores fixos.

A depreciação (D) foi calculada pela expressão:

$$
\mathrm{D}=\underline{\mathrm{V}_{\mathrm{a}}}-\mathrm{V}_{\mathrm{r}}
$$

em que $V_{a}$ (valor atual) é o valor do recurso, adquirido naquele momento (valor de um bem novo); $\mathrm{V}_{\mathrm{r}}$ (valor residual) é o valor de revenda ou valor final do bem, após ser utilizado de forma racional na atividade; e $\mathrm{V}_{\mathrm{u}}$ (vida útil) é o período em anos ou meses pelo qual determinado bem é utilizado na atividade produtiva (Reis, 2002).

Os custos variáveis foram compostos pelos insumos (suplementos alimentares, medicamentos, vacinas, mão-de-obra, despesas gerais, manutenção, energia elétrica, impostos, etc.), e o custo fixo pelo valor de depreciação de benfeitorias, de máquinas e equipamentos e de pastagens. Foi calculada a taxa de juros de $6 \%$ ao ano, isto é, o custo de oportunidade, sobre o capital investido nos custos fixos e nos variáveis, além do patrimônio - terras, benfeitorias, equipamentos e rebanho. $\mathrm{O}$ custo total foi calculado pela soma dos custos fixos, dos custos variáveis e dos custos de oportunidade (Tab. 2), conforme Reis (2002).

A receita bruta foi calculada com base no ganho em peso do animal em arrobas (peso vivo multiplicado pela média do rendimento de carcaça de $52 \%$ ) em cada tratamento, multiplicado pelo preço da arroba vendida a $\mathrm{R} \$ 56,00$. Como indexador foi utilizada a média do índice geral de preço disponibilidade interna (IGP-DI), de março de 2003, conforme Nehmi Filho (2002).

A margem bruta foi calculada subtraindo-se os custos variáveis do valor da receita bruta. Ao se retirarem desse valor os custos fixos, foi obtido o lucro operacional, que, por sua vez, subtraindo-se os custos de oportunidade resultou no resíduo para remuneração (Reis, 2002). 
Tabela 2. Valores utilizados na avaliação econômica a serem utilizados em uma propriedade de gado de corte

\begin{tabular}{|c|c|c|c|c|}
\hline Patrimônio & Qtde. & Valor unitário (R\$) & \multicolumn{2}{|c|}{ Valor total $(\mathrm{R} \$)$} \\
\hline Terras & 150ha & $2.000,00$ & \multicolumn{2}{|c|}{$300.000,00$} \\
\hline Gado & 176 novilhos & 400,00 & \multicolumn{2}{|c|}{$70.400,00$} \\
\hline Benfeitorias & 1 unidade & $29.600,00$ & \multicolumn{2}{|c|}{$29.600,00$} \\
\hline Subtotal & & & \multicolumn{2}{|c|}{$400.000,00$} \\
\hline Custos fixos anuais & Qtde. & Valor unitário (R\$) & Valor total $(\mathrm{R} \$)$ & R\$/novilho/período \\
\hline Benfeitorias & 1 unidade & $2.510,00$ & $2.510,00$ & 4,10 \\
\hline Máquinas e equipamentos & 1 unidade & 150,00 & 150,00 & 0,25 \\
\hline Pastagens & 90ha & 115,00 & $10.350,00$ & 16,92 \\
\hline Cercas & $7 \mathrm{~km}$ & 190,00 & $1.330,00$ & 2,17 \\
\hline Subtotal & & \multicolumn{3}{|c|}{$14.340,00$} \\
\hline Custos variáveis anuais & Qtde. & Valor unitário $(\mathrm{R} \$)$ & Valor total $(\mathrm{R} \$)$ & $\mathrm{R} \$$ /novilho/período \\
\hline Mão-de-obra & 1 empregado & $6.360,00$ & $6.360,00$ & 10,40 \\
\hline Despesas gerais & 1 unidade & $1.100,00$ & $1.100,00$ & 1,80 \\
\hline Manutenção & 1 unidade & $1.500,00$ & $1.500,00$ & 2,40 \\
\hline Medicamentos e vacinas & 1 unidade & 5,00 & & 2,06 \\
\hline SM & $1 \mathrm{~kg}$ & 0,640 & & 2,28 \\
\hline SUP 1 & $1 \mathrm{~kg}$ & 0,595 & & 26,30 \\
\hline SUP 2 & $1 \mathrm{~kg}$ & 0,422 & & 39,88 \\
\hline Subtotal & & \multicolumn{3}{|c|}{$8.960,00$} \\
\hline Juros de capital & 105 dias $(\%)$ & Valor /novilho (R\$) & \multicolumn{2}{|c|}{ Valor total $(\mathrm{R} \$)$} \\
\hline Custo fixo & 1,72 & 23,44 & \multicolumn{2}{|c|}{0,403} \\
\hline Custo variável - SM & 1,72 & 9,47 & \multicolumn{2}{|c|}{0,163} \\
\hline Custo variável - SUP1 & 1,72 & 21,48 & \multicolumn{2}{|c|}{0,369} \\
\hline Custo variável - SUP2 & 1,72 & 29,41 & \multicolumn{2}{|c|}{0,506} \\
\hline Patrimônio & 1,72 & 653,80 & \multicolumn{2}{|c|}{11,245} \\
\hline
\end{tabular}

SM: suplemento mineral; SUP1: suplemento protéico com média de ingestão diária de $0,17 \%$ do peso vivo.

SUP2: suplemento protéico com média de ingestão diária de 0,37\% do peso vivo. IGP-DI (março de 2003): 285,64.

\section{RESULTADOS E DISCUSSÃO}

A suplementação protéico-energética resultou em maior $(\mathrm{P}<0,05)$ média de ganho diário (GMD) (Tab. 3). Não ocorreu, entretanto, diferença significativa entre os dois níveis de suplementação protéico-energética. $\mathrm{O}$ efeito da covariável peso inicial não foi estatisticamente significativo.

Tabela 3. Médias de peso vivo inicial (PVI), de peso vivo final (PVF), de ganho total (GMT), de ganho diário (GMD) e de consumo de suplemento (CS) e coeficiente de variação (CV), de acordo com os tratamentos

\begin{tabular}{lcccc}
\hline & SM & SUP1 & SUP2 & CV (\%) \\
\hline PVI (kg) & 219 & 209 & 206 & 19,62 \\
PVF (kg) & 275 & 277 & 284 & 16,69 \\
GMT (kg/novilho)* & $56,1 \mathrm{a}$ & $68,8 \mathrm{~b}$ & $78,3 \mathrm{~b}$ & 19,90 \\
GMD (kg/novilho/dia)* & $0,535 \mathrm{a}$ & $0,655 \mathrm{~b}$ & $0,746 \mathrm{~b}$ & 19,91 \\
\hline CS (kg/novilho/dia) & 0,034 & 0,421 & 0,900 & \\
CS (\% da média peso vivo) & 0,01 & 0,17 & 0,37 & \\
\hline
\end{tabular}

SM: suplemento mineral; SUP1: suplemento protéico com média de ingestão diária de $0,17 \%$ do peso vivo;

SUP2: suplemento protéico com média de ingestão diária de $0,37 \%$ do peso vivo.

*Médias de ganho de peso com letras diferentes, na mesma linha, diferem entre si $(\mathrm{P}<0,05)$.

A diferença de GMD entre os tratamentos SUP1 e $\mathrm{SM}$, foi de $0,120 \mathrm{~kg} /$ novilho/dia e entre SUP 2 e SM de $0,211 \mathrm{~kg} /$ novilho $/$ dia. Estes valores estão próximos dos citados por Paulino et al. (2002), que mostraram acréscimos no GMD de 0,2 a $0,3 \mathrm{~kg} /$ animal $/$ dia com suplementação, durante a época das águas. Outros autores verificaram resultados semelhantes, quando compararam a suplementação protéica com a suplementação mineral, durante a época das águas. Alcalde et al. (2002) forneceram suplemento com $41 \%$ de PB a novilhos, cuja média de consumo foi de $0,81 \mathrm{~kg}$ por animal/dia, em pastagens de Brachiaria brizantha cv. Marandu, com média de 6,7\% de PB. Esses autores encontraram maior ganho em peso diário com a suplementação protéica, $1,06 \mathrm{~kg} /$ animal, em 
relação à suplementação somente com minerais, $0,72 \mathrm{~kg} /$ animal. Goes et al. (2003) verificaram maior média de ganho com a suplementação protéica, comparada com o suplemento mineral, cujos valores foram de $0,60,0,76,0,88 \mathrm{~kg} / \mathrm{animal}$ com suplementação mineral, suplementação diária de $0,23 \mathrm{~kg}$ da mistura múltipla $(\mathrm{MM})$ de farelo de trigo e farelo de soja e suplementação diária de $0,20 \mathrm{~kg}$ da MM de milho, farelo de trigo e uréia, respectivamente, e também não observaram diferenças significativas na média do ganho diário entre as suplementações protéicas, com animais colocados em pastagens de Brachiaria radicans e Melinis minutiflora.

Trabalhos que utilizaram outras gramíneas também mostraram maior ganho médio diário de bovinos que consumiram suplementos protéico-energéticos, com acréscimos médios que variaram de 0,07 a $0,378 \mathrm{~kg} / \mathrm{cabeça} / \mathrm{dia}$, comparados aos que consumiram somente minerais durante a época das águas (Villela et al. 2003; Peres et al., 2005).

Os resultados econômicos (Tab. 4) mostraram que os três tratamentos foram economicamente viáveis, isto é, apresentaram resultado positivo. O ganho de peso dos animais, no período, pagou os custos variáveis, os custos fixos e os juros, e deixou, ainda, um resíduo para a remuneração do proprietário. Cabe salientar que essa análise é temporal e não pode ser extrapolada para todo o ano, porque o ganho de peso dos animais e o custo da suplementação se alteram ao longo do ano. O SUP2 apresentou maior receita bruta, maior margem bruta, maior lucro operacional e maior resíduo para remuneração em relação ao SUP1. Este, por sua vez, foi melhor que o SM. O lucro operacional ( $\mathrm{R} \$ /$ animal/período) e o resíduo para remuneração (R\$/animal/período), segundo o tratamento, são mostradas na Tab. 4.

Tabela 4. Avaliação econômica de uma criação de novilhos de corte de acordo com as suplementações (R\$/animal/período)

\begin{tabular}{lccc}
\hline & SM & SUP1 & SUP2 \\
\hline Custos variáveis (CV) (R\$/animal/período*) & 18,94 & 42,96 & 56,54 \\
\hline Suplementação & 2,28 & 26,30 & 39,88 \\
Medicamentos e vacinas & 2,06 & 2,06 & 2,06 \\
Mão-de-obra & 10,40 & 10,40 & 10,40 \\
Despesas gerais e manutenção & 4,20 & 4,20 & 4,20 \\
\hline Custos fixos (CF) (R\$/animal/período) & 23,44 & 23,44 & 23,44 \\
\hline Benfeitorias e equipamentos & 4,35 & 4,35 & 4,35 \\
Pastagens & 16,92 & 16,92 & 16,92 \\
Cercas & 2,17 & 2,17 & 2,17 \\
\hline Fixos + variáveis (R\$/animal/período) & 42,38 & 66,40 & 79,98 \\
\hline Juros sobre CF + CV (R\$/animal/período) & 0,57 & 0,77 & 0,91 \\
Juros sobre patrimônio** (R\$/animal/período) & 11,25 & 11,25 & 11,25 \\
\hline Custo total (R\$/animal/período) & 54,20 & 78,42 & 92,14 \\
\hline Receita bruta (R\$/animal/período) & 109,05 & 133,52 & 152,06 \\
Margem bruta (R\$/animal/período) & 90,11 & 90,56 & 95,52 \\
Lucro operacional (R\$/animal/período) & 66,67 & 67,12 & 72,08 \\
Resíduo p/remuneração (R\$/animal/período) & 54,85 & 55,10 & 59,92 \\
\hline
\end{tabular}

*Período $=105$ dias.

**Patrimônio $=$ Terras, benfeitorias, equipamentos e rebanho.

SM: suplemento mineral; SUP1: suplemento protéico com média de ingestão diária de $0,17 \%$ do peso vivo.

SUP2: suplemento protéico com média de ingestão diária de $0,37 \%$ do peso vivo.

A viabilidade econômica da suplementação protéico-energética do pasto, durante a época de transição água-seca e encontrada neste trabalho, assemelha-se aos resultados de Euclides (2001), Tomich et al. (2002) e Peres et al. (2005), que também verificaram melhor resultado econômico nos tratamentos com suplementação protéicoenergética do pasto quando comparada com o tratamento-controle.

Euclides (2001) forneceu a novilhos uma mistura múltipla à base de $0,2 \%$ do peso vivo, em pastagens de Brachiaria decumbens e Brachiaria brizantha, durante a época das águas. Os novilhos no pasto suplementado apresentaram média de ganho de $740 \mathrm{~g} /$ dia e os sem suplementação, de $535 \mathrm{~g} /$ dia. O custo da suplementação foi de R\$ 26,00/novilho/período, e a diferença de 205g/animal/dia, em 184 dias, significou 36,8kg de peso vivo, com a receita adicional de $\mathrm{R} \$ 56,00$ (arroba vendida $=\mathrm{R} \$ 44,00$ ).

Tomich et al. (2002) não verificaram diferença estatística no ganho de peso de novilhos Nelores em 
pastos de Brachiaria brizantha e de Brachiaria ruziziensis, suplementados com mistura múltipla, durante a época das águas, com consumo de $168 \mathrm{~g} / \mathrm{animal} /$ dia. Entretanto, ao analisarem o lucro por animal (receita menos o custo da suplementação) encontraram R \$ 86,40/animal para a mistura múltipla e $\mathrm{R} \$ 84,09$ /animal para o suplemento mineral (controle), isto é, a relação custo:benefício foi $21 \%$ mais alta para a mistura múltipla. Peres et al. (2005) compararam o desempenho de novilhas manejadas em capimelefante (Pennisetum purpureum cv. Napier) com suplementação de milho e farelo de soja (média de ingestão diária de $0,5 \%$ do peso vivo) e suplementação de leguminosa (Stylosanthes guianensis, cv. Mineirão). O retorno econômico avaliado pela taxa interna de retorno (TIR), que é a taxa de desconto que iguala o valor presente dos benefícios de um projeto ao valor presente de seus custos (Contador, 1988), mostrou maior viabilidade para o tratamento com milho e farelo de soja comparada ao ao tratamento-controle e ao tratamento com leguminosa, sendo os valores calculados da TIR de 30,1\%, 29,6\% e 10,5\%, respectivamente.

\section{CONCLUSÃO}

Pode-se recomendar a suplementação protéicoenergética para novilhos criados em pasto, pois o retorno econômico é maior do que o observado para os que só consomem suplemento mineral, na época de transição entre o período das águas e da seca.

\section{REFERÊNCIAS BIBLIOGRÁFICAS}

ALCALDE, C.R.; GARCIA, J.; ANDRADE, P. et al. Suplementação protéica em pastagens de Brachiaria brizantha no período das águas. In: REUNIÃO ANUAL DA SOCIEDADE BRASILEIRA DE ZOOTECNIA, 39., 2002, Recife. Anais... Recife: SBZ, 2002. CD-ROM. (Resumo). BARBOSA, F.A.; GRAÇA, D.S.; MAFFEI, W.E. et al. Desempenho e consumo de matéria seca de bovinos sob suplementação protéico-energética, durante a época de transição água-seca. Arq. Bras. Med. Vet. Zootec., v.59, p.160-167, 2007.

CARVALHO, F.A.N.; BARBOSA, F.A.; McDOWELL, L.R. Nutrição de bovinos a pasto. Belo Horizonte: PAPELFORM, 2003. 438p.

CONTADOR, C.R. Indicadores para seleção de projetos. In: CONTADOR, C. (Ed). Avaliação social de projetos. 2.ed. São Paulo: Atlas, 1988. p.41-58.

EUCLIDES, V.P.B. Produção intensiva de carne bovina em pasto. In: SIMPÓSIO DE PRODUÇÃO DE GADO DE CORTE, 2., 2001, Viçosa. Anais ... Viçosa: UFV, 2001. p.5582.

FRANK, R. G. Introducción al calculo de costos agropecuarios. Buenos Aires: El Ateneo, 1978.
GOES, R.H.T.B.; MANCIO, A.B.; LANA, R.P. et al. Desempenho de novilhos Nelore em pastejo na época das águas: ganho de peso, consumo e parâmetros ruminais. Rev. Bras. Zootec., v.32, p.214-221, 2003.

MORAES, E.H.B.K.; PAULINO, M.F.; ZERVOUDAKIS, J.T. et al. Níveis de proteína em suplementos para novilhos mestiços em pastejo durante o período de transição seca/águas. Rev. Bras. Zootec., v.35, p.2135-2143, 2006.

LOOSLI, J.K.; McDONALD, I.W. El nitrogeno no proteico en la nutrición de los rumiantes. Roma: FAO, 1969.

NEHMI FILHO, V.A. O IGP é o verdadeiro indexador do boi. In: Anualpec 2002: Anuário da pecuária brasileira. FNP Consultoria \& Comércio, Boviplan Consultoria Agropecuária. São Paulo: Argos Comunicação, 2002. p.105106.

NUTRIENT requeriments of beef cattle. 7.ed. Washington: National Academy of Sciences, 1996. 242p.

PAULINO, M.F.; ZERVOUDAKIS, J.T.; DE MORAES, E.H.B.K. et al. Bovinocultura de ciclo curto em pastagens . In: SIMPÓSIO DE PRODUÇÃO DE GADO DE CORTE, 3., 2002, Viçosa. Anais ... Viçosa: UFV, 2002. p.153-196.

PERES, A.A.C.; VASQUEZ, H.M.; SILVA, J.F.C et al. Avaliação produtiva e econômica de sistemas de produção bovina em pastagens de capim-elefante. Arq. Bras. Med. Vet. Zootec., v.57, p.367-373, 2005.

REIS, R.A.; RODRIGUES, L.R.A.; PEREIRA, J.R.A. Suplementação como estratégia de manejo de pastagem. In: SIMPÓSIO SOBRE MANEJO DE PASTAGEM, 13., 1997, Piracicaba. Anais ... Piracicaba : FEALQ. 1997. p.123-150.

REIS, R.P. Fundamentos de economia aplicada. Lavras: UFLA/FAEPE, 2002. 95p.

SAMPAIO, I.B.M. Estatística aplicada à experimentação animal. 2.ed. Belo Horizonte: FEPMVZ, 2002. 265p.

SILVA, F.F.; VALADARES FILHO, S.C.; ÍTAVO, L.C.V. et al. Exigências líquidas e dietéticas de energia, proteína e macroelementos minerais de bovinos de corte no Brasil. Rev. Bras. Zootec., v.31, p.776-792, 2002.

TOMICH, T.R.; LOPES H.O.S.; PIRES, D.A.A. et al. Suplementação com mistura múltipla contendo uréia como fonte de nitrogênio para bovinos em pastagens de braquiária no período das águas. In: REUNIÃO ANUAL DA SOCIEDADE BRASILEIRA DE ZOOTECNIA, 39., 2002. Recife. Anais ... Recife: SBZ, 2002. CD-ROM.

USER'S guide:statistics. Version 6. 4.ed. Cary, NC: SAS Institute, 1990.

VAN SOEST, P.J. Nutritional ecology of the ruminant. 2.ed. Ithaca: Cornell University, 1994. 476p.

VILLELA, S.D.J.; PAULINO, M.F.; VALADAES FILHO, S.C. et al. Efeito da suplementação com diferentes fontes de proteína para bovinos de corte em pastejo no período das águas. 1- desempenho. In: REUNIÃO ANUAL DA SOCIEDADE BRASILEIRA DE ZOOTECNIA, 40., 2003, Santa Maria. Anais... Santa Maria: SBZ, 2003. CD-ROM. (Resumo). 